\title{
ANÁLISE DE CRESCIMENTO EM FEIJOEIRO CULTIVADO SOB DIFERENTES DENSIDADES DE SEMEADURA
}

\section{GROWTH ANALYSIS IN COMMON BEAN CULTIVATED UNDER DIFFERENT SEEDING DENSITIES}

\author{
Raphael Rossi SILVA \\ Silvia SCARIOTTO ${ }^{2}$ \\ Gustavo MALAGI ${ }^{3}$ \\ José Abramo MARCHESE ${ }^{4}$
}

\section{RESUMO}

O objetivo do estudo foi avaliar por meio da análise de crescimento, as variações nas características fisiológicas do feijoeiro comum, cultivar IPR Tiziu, submetidos a diferentes densidades de semeadura, buscando identificar a melhor disposição espacial das plantas. O delineamento experimental foi de blocos ao acaso com quatro repetições, os tratamentos consistiram de cinco densidades de semeadura (DS): 8, 10,12, 14 e 18 plantas $\mathrm{m}^{-1}$, respectivamente, 20, 25, 30,35, 40 pl m 2. Para avaliação, semanalmente coletaram-se 12 plantas de cada parcela. Os resultados evidenciaram aumento do índice de área foliar (IAF) e da matéria seca total (MST) até 57 dias após a emergência (DAE), enquanto a taxa de crescimento da cultura (TCC), taxa de crescimento relativo (TCR), taxa assimilatória líquida (TAL) e razão de área foliar (RAF) apresentaram redução durante o ciclo da cultura. A DS de $30 \mathrm{pl} \mathrm{m}^{-2}$ foi a mais eficiente no aproveitamento dos recursos do ambiente quanto à conversão de energia luminosa e $\mathrm{CO}_{2}$ em MST, já que apresentou os maiores valores de MST, TCC e TAL. Entretanto, os tratamentos não diferiram significativamente entre si para os componentes do rendimento e rendimento de grãos. A maior DS promoveu menor TAL, TCC, RAF devido ao aumento do IAF, o que provocou auto-sombreamento na cultura, diminuindo a eficiência fotossintética do feijoeiro.

Palavras-chave: Phaseolus vulgaris; rendimento; índices fisiológicos; espaçamento.

\section{ABSTRACT}

The aim of this study was to evaluate by growth analysis (GA) changes in physiological characteristics of common bean, IPR Tiziu cultivar, subjected to different seeding densities (SD) in order to identify the best spatial arrangement of plants. The experimental design was a randomized block with four replicates. The treatments consisted of five DS: $8,10,12$, 14 and 18 plants $\mathrm{m}^{-1}$, respectively, $20,25,30,35,40 \mathrm{pl} \mathrm{m}^{-2}$. For evaluations, 12 plants were collected from each plot weekly. Twelve plants from each plot were collected for GA and the results evidenced an increase of leaf area index (LAI) and total dry matter (TDM) until 57 days after emergence (DAE), while crop growth rate (CGR), relative growth rate (RGR), net assimilation rate (NAR) and leaf area ratio (LAR) decreased as the crop developed. SD of 30 plant $\mathrm{m}^{-2}$ was the most efficient in the utilization of environmental resources related to conversion of luminous energy and $\mathrm{CO}_{2}$ in dry matter because the values of TDM, CGR and NAR were higher. However, treatments did not differ significantly between themselves for yield components and grain yield, despite SD of 30 plant $\mathrm{m}^{-2}$ has presented $600 \mathrm{~kg} \mathrm{ha}^{-1}$ higher yield when compared to the lower grain yield. The use of higher SD causes significant decrease of NAR, CGR, LAR due to the increase of LAI that causes more auto-shading on the crop, decreasing the photosynthetic efficiency of common bean.

Key-words: Phaseolus vulgaris; yield; physiological indices; plant spacing.

\footnotetext{
Eng. Agr., MSc., Doutorando do Programa de Pós Graduação em Agronomia da Universidade Estadual de Londrina. Londrina, PR, BR. e-mail: raphaelrossi@agronomo.eng.br.

$\frac{1}{2}$ Eng. Agr., MSc. Em Agronomia. Pato Branco, PR, BR. e-mail: silviascariotto@yahoo.com.br.

${ }^{3}$ Eng. Agr., MSc., Doutorando do Programa de Pós Graduação em Agronomia da Universidade Federal de Pelotas. Pelotas, RS, BR. e-mail: malagi@agronomo.eng.br.

${ }^{4}$ Eng. Agr., Phd., Professor do Programa de Pós Graduação em Agronomia da Universidade Tecnológica Federal do Paraná - UTFPR, Campus Pato Branco. Rodovia do Conhecimento Km 1, CEP 85503-390, Pato Branco, PR, BR. e-mail: abramo@pq.cnpq.br
} 
SILVA, R.S., et al. Análise de crescimento em...

\section{INTRODUÇÃO}

A análise de crescimento é muito utilizada para estudos de variação do crescimento vegetal, quer seja por alterações de ordem genética, ou resultado de modificações ambientais (Benincasa, 2003; Loomis \& Connors, 2002). Essa análise descreve as condições morfofisiológicas da planta, em diferentes intervalos de tempo, permitindo acompanhar a dinâmica da produtividade através de parâmetros fisiológicos e bioquímicos, em que a determinação da área foliar é importante, pois as folhas são as principais responsáveis pela captação de energia solar e subsequente transformação desta em matéria seca, por meio da fotossíntese (Benincasa, 2003). Assim, ao se conhecer a superfície foliar e a alteração da massa da planta durante um determinado período de tempo, torna-se possível avaliar a eficiência das folhas e sua contribuição para o crescimento da planta como um todo.

A análise de crescimento é amplamente utilizada em diferentes áreas, como no melhoramento genético de plantas (Spitters \& Kramer, 1986), fisiologia vegetal (Rodgers \& Barneix, 1988), ecologia de diferentes espécies e em análises comparativas entre plantas daninhas e culturas (Erasmo et al., 1997; Silva \& Marenco, 2000), na diferença de crescimento entre plantas daninhas resistentes e suscetíveis a herbicidas (Vidal \& Trezzi, 2000; Brighenti et al., 2001; Christoffoleti, 2001) e influência das práticas agronômicas sobre o crescimento (Barreiro et al., 2006). Esta análise se baseia em diversos índices fisiológicos para análise quantitativa do crescimento de plantas, tais como a taxa de crescimento absoluta (TCA), taxa de crescimento relativa (TCR), taxa de assimilação líquida (TAL), razão de área foliar (RAF), área foliar específica (AFE), razão de peso da folha (RPF), duração da área foliar (DAF) e índice de área foliar (IAF). Em virtude da análise de crescimento estar baseada na determinação das variações morfológicas das plantas, pode ser utilizada de forma segura, na avaliação do crescimento final das plantas e no conhecimento da contribuição de cada órgão no crescimento total, pois cerca de $90 \%$ da matéria seca acumulada é resultante da atividade fotossintética, sendo o restante acumulado pela absorção de nutrientes do solo (Benincasa, 2003)

A densidade de plantas é prática cultural que possui vários estudos objetivando identificar a densidade que proporciona maior rendimento de grãos, já que é de fácil utilização e de pouco impacto no custo de produção. Valério et al. (1999) observaram que o incremento da população de feijoeiro reduziu o número de vagens por planta e o número de grãos por vagem, mas a produtividade por área manteve-se estável. Entretanto, Shimada et al. (2000) obtiveram o maior rendimento de grãos quando o espaçamento entre linhas foi de $0,3 \mathrm{~m}$ e a densidade de plantas de $8 \mathrm{pl} \mathrm{m}^{-1}$, indicando que o aumento na população de plantas não resultou em maior rendimento de grão por área, confirmando resultados obtidos por Teixeira et al. (2000) em que verificaram estabilidade no rendimento de grãos nas diferentes densidades de semeadura.
O objetivo do estudo foi avaliar por meio da análise de crescimento, as variações na resposta de características fisiológicas do feijoeiro comum, submetido a diferentes densidades de semeadura, buscando identificar a melhor disposição espacial das plantas.

\section{MATERIAL E MÉTODOS}

O experimento foi implantado em 04/02/2010 na área experimental do Curso de Agronomia da Universidade Tecnológica Federal do Paraná, situada no município de Pato Branco, Paraná, com as seguintes coordenadas geográficas: latitude de $26^{\circ} 41^{\prime} \mathrm{S}$ e longitude $56^{\circ} 07^{\prime} \mathrm{W}$ e uma altitude de $730 \mathrm{~m}$. O solo local é classificado como LATOSSOLO VERMELHO Distroférrico úmbrico, textura argilosa, álico, fase floresta subtropical perenifólia (BHERING et al., 2008). O clima do tipo Cfa (Classificação de Köeppen).

$O$ delineamento experimental foi de blocos ao acaso, com quatro repetições, sendo os tratamentos compostos por diferentes densidades de semeadura na linha, $8,10,12,14$ e $16 \mathrm{pl} \mathrm{m}^{-1}$, correspondendo a $20,25,30,35$ e 40 plantas $\mathrm{m}^{-2}$, respectivamente, com espaçamento entre linha de 0,40 $\mathrm{m}$. As unidades experimentais apresentavam 4,4 m de comprimento e 5,0 m de largura, totalizando 12 linhas, em que uma linha de cada lado unidade experimental foi considerada como bordadura, perfazendo uma área total de $22,0 \mathrm{~m}^{2}$. A adubação de base foi realizada de acordo com o resultado da análise de solo, utilizando $140 \mathrm{~kg} \mathrm{ha}^{-1}$ da formulação 8-20-20 (N-P-K) e $45 \mathrm{~kg} \mathrm{ha}^{-1}$ de $\mathrm{N}$ em cobertura aos 30 dias após a emergência (DAE) na forma de uréia. A cultivar utilizada foi a IPR Tiziu, de hábito de crescimento indeterminado e porte ereto que favorece a colheita mecânica direta com alto potencial de rendimento de grão e de ampla adaptação.

Para a semeadura, foi feita a contagem manual das sementes para cada linha com sua respectiva densidade de semeadura, corrigida para o poder germinativo de $95 \%$ para obtenção do estande desejado. Foi observada emergência no quarto dia após a semeadura. Os tratos culturais realizados consistiram de aplicações de herbicidas fluazifop-p-butil $\left(200 \mathrm{~g} \mathrm{~L}^{-1}\right.$ de i.a.) + fomesafen $\left(250 \mathrm{~g} \mathrm{~L}^{-1}\right.$ de i.a.) na dosagem de $800 \mathrm{~mL} \mathrm{ha}^{-1}$ aos $15 \mathrm{DAE}$ aplicação do fungicida metamitrona $\left(400 \mathrm{~g} \mathrm{~L}^{-1}\right.$ i.a. $)$ na dose de $325 \mathrm{~mL} \mathrm{ha}^{-1}$ aos 20,35 e 50 DAE e, piraclostrobina ( $250 \mathrm{~g} \mathrm{~L}^{-1}$ i.a.) na dose de $300 \mathrm{~mL}$ ha ${ }^{-1}$ aos 20,35 e 50 DAE. Realizaram-se também aplicações de acaricida/inseticida abamectina (18 g $\mathrm{L}^{-1}$ de i.a.) na dose de $300 \mathrm{~mL} \mathrm{ha}^{-1}$ aos 20,35 e 50 DAE e, methamidophos (600 $\mathrm{g} \mathrm{L}^{-1}$ de i.a) na dose de $500 \mathrm{~mL} \mathrm{ha}^{-1}$ aos 20,40 e 60 DAE.

As determinações para análise de crescimento seguiram a metodologia proposta por Benincasa (2003) retirando-se 12 plantas de cada parcela em coletas realizadas aos $15,22,29,36,43,50$ e 57 DAE. Para o cálculo da área foliar foi realizada a somatória das áreas de todas as lâminas foliares da planta em $\mathrm{cm}^{2}$, com a utilização de um integrador de área foliar modelo LI-3100 (LI-COR, Lincon, Nebrasca - USA). Para obtenção da massa verde, a planta 
foi separada em raiz, caule, pecíolo, folha, flor e vagens, e pesados separadamente. A massa seca foi pesada após a secagem das partes das plantas em estufa até peso constante a temperatura de $60^{\circ} \mathrm{C}$. A massa total correspondeu à soma das massas de todos os órgãos existentes, em cada coleta.

Foi calculado o índice de área foliar (IAF) médio de cada tratamento, em cada época de avaliação. Os dados relativos ao IAF alimentaram a entrada de dados do aplicativo ANACRES (Portes \& Castro Júnior, 1991), sendo obtidas equações para, taxa assimilatória liquida ( $T A L)$, taxa de crescimento relativo (TCR), razão de área foliar (RAF), taxa de crescimento da cultura (TCC) e, área foliar específica (AFE). Estas taxas e razões são definidas abaixo:

Taxa assimilatória liquida

$$
T A L=\frac{(b+2 c t) \cdot a \cdot e^{\left(b t+c t^{2}\right)}}{a_{1} \cdot e^{\left(b_{1}+c_{1} t^{2}\right)}}
$$

A TAL $\left(\mathrm{g} \mathrm{dm}^{-2} \mathrm{dia}^{-1}\right)$ expressa a taxa de fotossíntese líquida, em termos de massa seca produzida, em gramas, por decímetro quadrado de área foliar, por unidade de tempo (Benincasa, 2003);

Taxa de crescimento relativo

$$
T C R=d \ln \frac{a \cdot e^{\left(b t+c t^{2}\right)}}{d t}
$$

A TCR ( $\mathrm{g} \mathrm{g}^{-1}$ dia $\left.^{-1}\right)$, que é função do tamanho inicial, isto é, o aumento em gramas, no caso de massa seca, está relacionado ao peso de massa seca no instante em que se inicia o período de observação (Benincasa, 2003).

Razão de área foliar,

$$
R A F=\frac{A F}{M S T}
$$

A RAF $\left(\mathrm{dm}^{2} \mathrm{~g}^{-1}\right)$ expressa á área foliar útil para fotossíntese e é obtida a partir dos valores instantâneos da área foliar (AF), e massa seca total (MST), resultando na fotossíntese.

Taxa de crescimento da cultura

$$
T C C=(M S 2-M S 1 / t 2-t 1)
$$

A TCC $\left(\mathrm{g} \mathrm{pl}^{-1} \mathrm{dia}^{-1}\right)$ expressa a variação da matéria seca por unidade de área com o passar do tempo e representa a capacidade de produção de fitomassa da cultura.

Área foliar específica (AFE)

$$
A F E=A f / M S F
$$

A AFE é a componente morfológica e anatômica da RAF, pois relaciona a superfície com o peso da matéria seca da própria folha.

A avaliação dos componentes do rendimento foi realizada através da determinação do número de vagens por planta que foi utilizada para estimar o número de vagens por área, número de grão por vagens e peso de mil grãos, obtidos a par-
SILVA, R.S., et al. Análise de crescimento em...

tir da média de 12 plantas por unidade experimental. O rendimento de grãos foi determinado pela pesagem de grãos em uma área de $6,4 \mathrm{~m}^{2}$ coletadas manualmente, com trilha mecânica. A umidade foi corrigida para $13 \%$ e estimado para $\mathrm{kg} \mathrm{ha}^{-1}$.

As equações exponenciais obtidas pelo aplicativo ANACRES para cada taxa e razão são demonstradas graficamente ao longo deste trabaIho. Os dados relativos número de vagens por área, número de grãos por vagem, peso de mil grãos e rendimento de grãos, foram submetidos à análise dos pressupostos matemáticos pelo aplicativo computacional R (R Development Core Team, 2010) e, sendo estes atendidos, procedeu-se a análise de variância pelo mesmo aplicativo, seguido de análise de regressão para a variável rendimento de grãos.

\section{RESULTADOS E DISCUSSÃO}

De acordo com a análise de variância, verificou-se a interação significativa entre os fatores densidade de semeadura (DS) e época de avaliação (DAE) para as variáveis matéria seca total e IAF, sendo necessário o ajuste destas variáveis para cada DS em função do tempo, visando identificar o acúmulo de matéria seca total e, paralelamente, o IAF.

As curvas de ajustes da matéria seca total (MST) apresentaram acúmulo significativamente maior a partir dos 30 DAE até 50 DAE sendo influenciado pela DS, em que as maiores densidades apresentaram o maior acúmulo de MST (Figura 1). Os tratamentos com maior densidade $\left(35 \mathrm{pl} \mathrm{m}^{-2} \mathrm{e}\right.$ $40 \mathrm{pl} \mathrm{m}^{-2}$ ) apresentaram maior MST até aproximadamente $40 \mathrm{DAE}$, durante o período que a cobertura do solo, ocasionada pelas plantas de feijão, estava incompleta. Todavia, a partir dos 50 DAE houve inversão do limite superior de acúmulo, tendo a densidade de $30 \mathrm{pl} \mathrm{m}^{-2}$ o maior valor, de acordo com a tendência quadrática. Loomis \& Connor (2002) reportaram que plantas cultivadas em maiores densidades apresentam maior crescimento nas fases iniciais do cultivo, incrementando a interceptação de luz e a taxa de crescimento mais rapidamente que plantas cultivadas em menor densidade. Todavia, segundo os mesmos autores, os cultivos mais densos têm significativamente maior biomassa no início da estação de cultivo, mas a magnitude relativa desta vantagem se reduz à medida que a estação avança. A densidade de $30 \mathrm{pl} \mathrm{m}^{-2}$ pode ser considerada como o melhor arranjo de plantas por área, uma vez que após os 50 DAE a provável maior eficiência fotossintética das plantas submetidas a essa DS, contribuiu para a melhor distribuição de fotoassimilados entre os órgãos da planta, o que aliado a melhor condição nutricional foliar (Tabela 1), resultou no maior acúmulo de MST (Figura 1). O mesmo resultado pode ser verificado para a TCC em que a DS de $30 \mathrm{pl} \mathrm{m}^{-2}$ também foi o melhor tratamento. Esse fato pode ser devido ao menor efeito do auto-sombreamento para $30 \mathrm{pl} \mathrm{m}^{-2}$ em relação às plantas submetidas às maiores DS, que apresentaram um maior IAF no decorrer do ciclo (Figura 2). 
SILVA, R.S., et al. Análise de crescimento em...

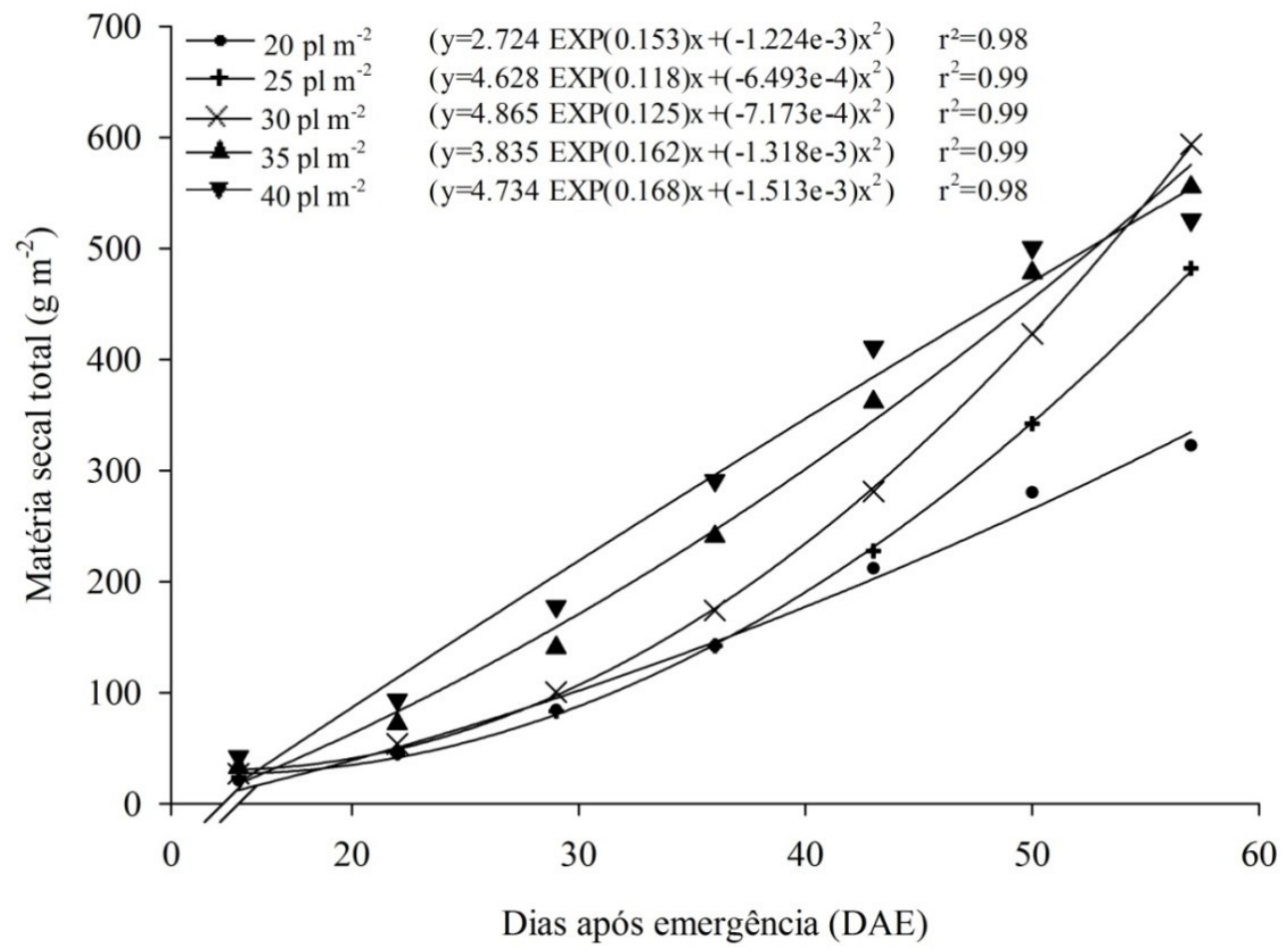

FIGURA 1. Evolução da matéria seca total $\left(\mathrm{g} \mathrm{m}^{-2}\right)$ de plantas de feijão comum submetidas a diferen-

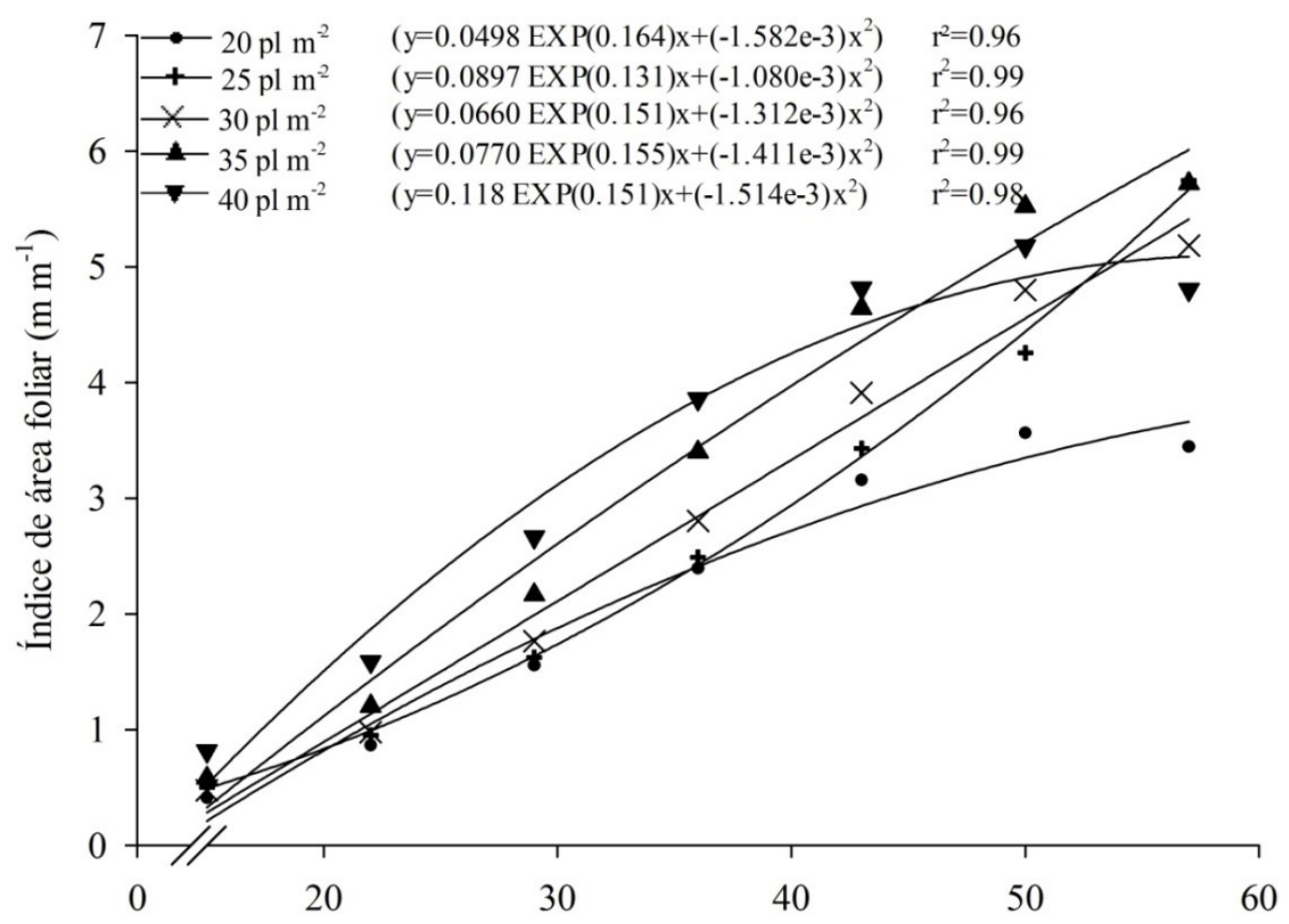

tes den-

Dias após emergência (DAE)

FIGURA 2. Evolução do IAF $\left(\mathrm{m}^{2} \mathrm{~m}^{-2}\right)$ de plantas de feijão comum submetidas a diferentes densidades de semeadura. 
As curvas ajustadas para o IAF nos diferentes períodos de avaliação após a emergência indicam que o valor máximo foi obtido, em todos os tratamentos, aos $57 \mathrm{DAE}$. Tais resultados corroboram com os obtidos por Urchei et al. (2000), Nobrega et al. (2001) e Jauer et al. (2003) em que o IAF máximo observado foi em torno de $60 \mathrm{DAE}$, indicando que para a cultura do feijoeiro o IAF máximo ocorre entre o pleno florescimento e o início da formação de vagens, variando de acordo com o ciclo de cada cultivar. Durante praticamente todo o ciclo de condução do experimento, os maiores IAFs observados foram para os tratamentos de maior DS (Figura 2), todavia, essa maior área foliar por unidade de superfície do solo não resultou em aumento de massa seca (Figura 1), pois elevados IAFs causados pelo adensamento excessivo das plantas promovem o sombreamento mútuo das folhas, reduzindo a fotossíntese líquida. Segundo Loomis \& Connor (2002), devido ao auto-sombreamento, a interceptação da radiação pelo dossel vegetal é
SILVA, R.S., et al. Análise de crescimento em...

uma função do IAF com pendente decrescente. Isso se deve à maior área foliar específica (AFE) observada nas maiores densidades, condição esta proporcionada pelo auto-sombreamento (Figura 3). Segundo Benincasa (2003) no início do desenvolvimento os valores da AFE podem ser maiores, indicando que as folhas são pouco espessas e com pouca massa seca e área foliar. Com o avanço do ciclo da cultura ocorre o aumento da área foliar e massa seca, tendendo a queda dos valores de AFE. No entanto, observou-se que independente da densidade de semeadura, ocorreu um decréscimo da AFE, 30 DAE seguido de um aumento, em razão da senescência natural das folhas. Porém, para o caso da densidade de semeadura de $30 \mathrm{pl} \mathrm{m}^{-2}$ a AFE apresentou oscilações menos marcantes em relação as demais, uma vez estar em nível intermediário em relação ao auto-sombreamento que se observa nas maiores densidades, e baixa área foliar encontrada em menores densidade de semeadura.

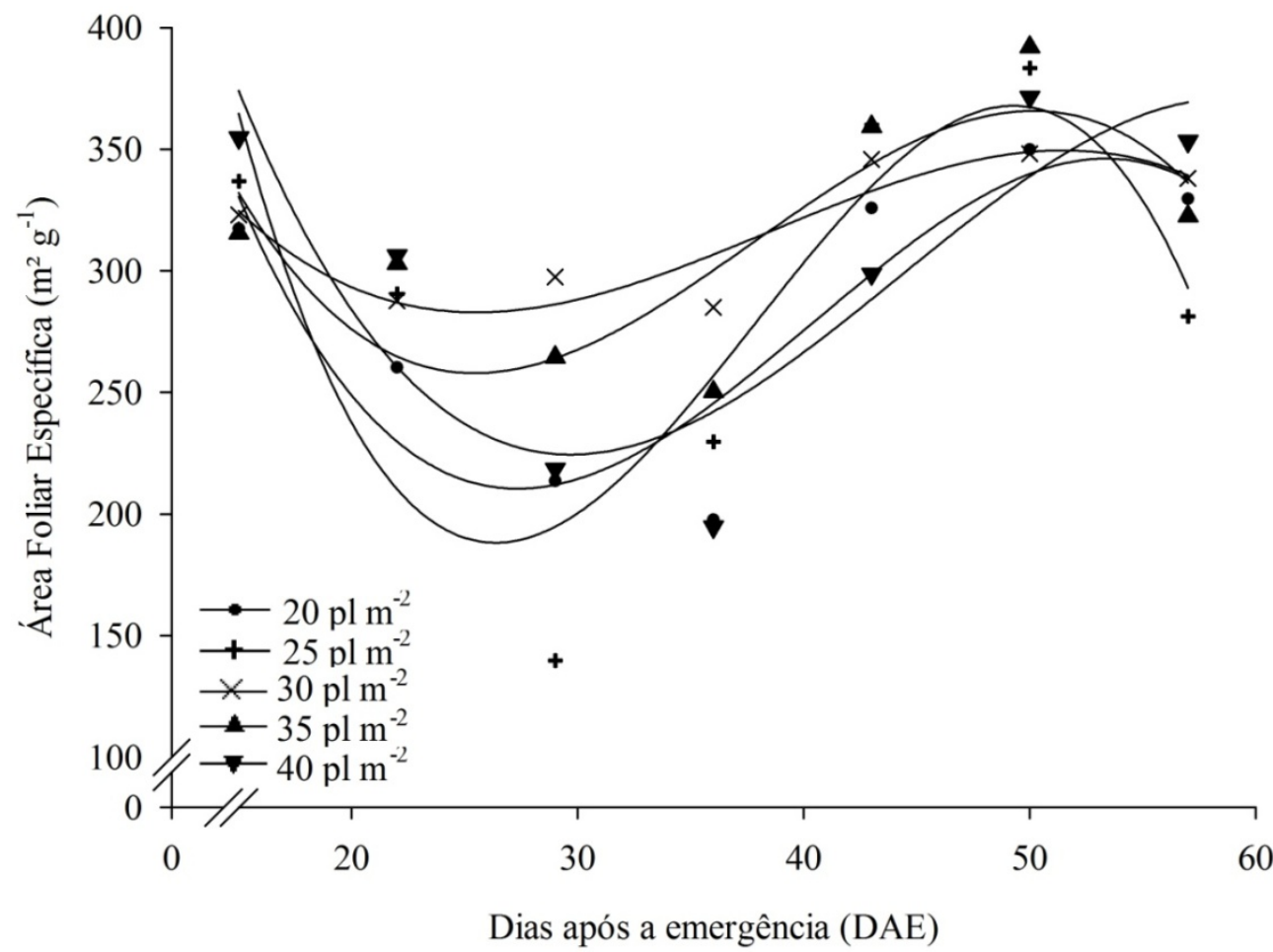

FIGURA 3. Área foliar específica $\left(\mathrm{m}^{2} \mathrm{~g}^{-1}\right)$ de plantas de feijão comum submetidas a diferentes densidades de semeadura.

Os resultados para IAF são corroborados pelas taxas de assimilação líquida (TAL) dos tratamentos, expostos na Figura 4, em que fica evidente a diminuição gradativa da TAL ao longo do ciclo da planta, o que é justificado devido ao maior IAF em altas densidades, com consequente redução do fluxo de fótons fotossintéticos de interceptação por área, provocando a diminuição da TAL em maiores densidades. Essa resposta foi observada para as DS de 35 e $40 \mathrm{pl} \mathrm{m}^{-2}$ e, também para a menor densidade em que há menor interceptação de radiação solar por área. Já as DS de 25 e $30 \mathrm{pl} \mathrm{m}^{-2}$ apresentaram alta interceptação da radiação solar fotossinteticamente ativa, contribuindo para que apresentassem os maiores valores de TAL. 
SILVA, R.S., et al. Análise de crescimento em...

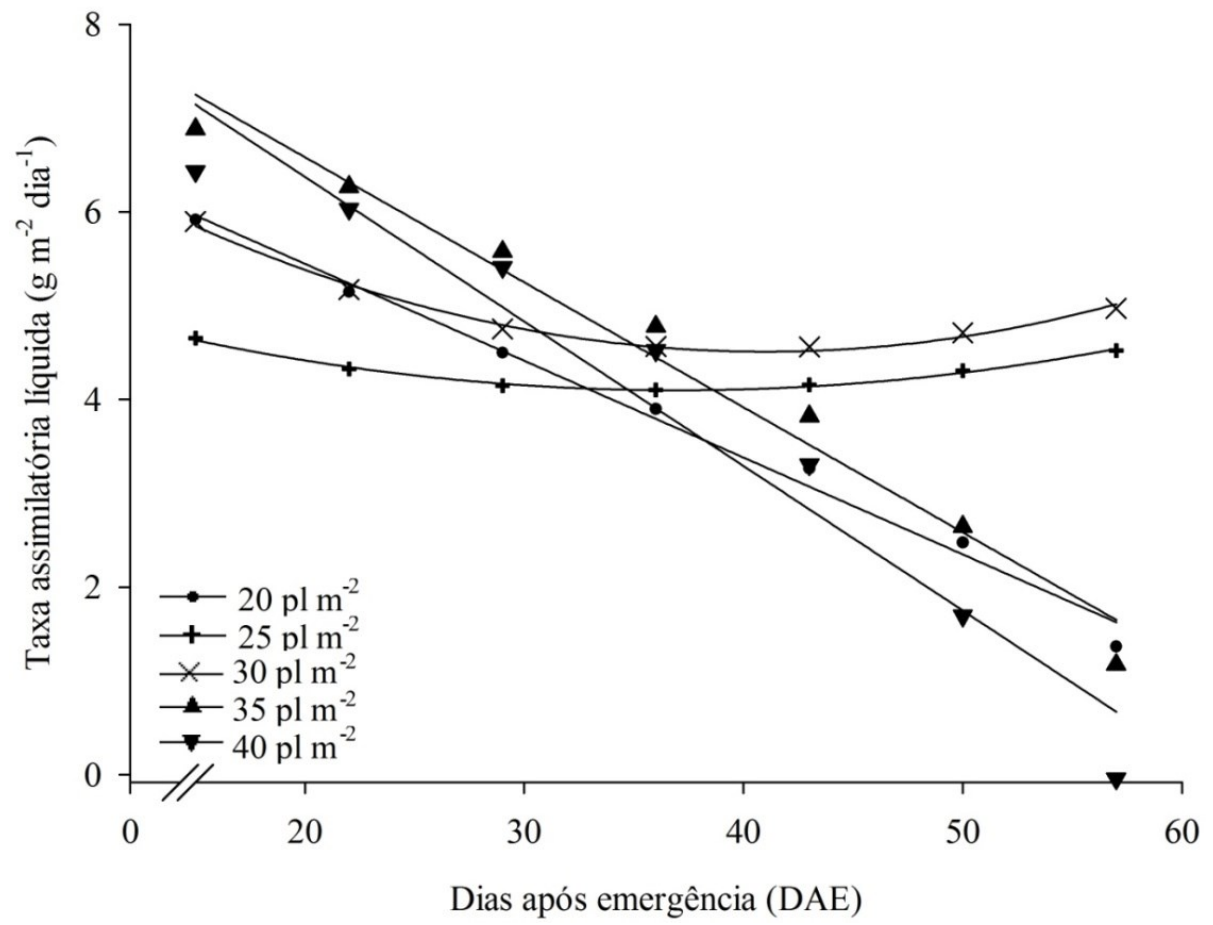

FIGURA 4. Taxa assimilatória líquida $\left(\mathrm{g} \mathrm{m}^{-2} \mathrm{dia}^{-1}\right)$ de plantas de feijão comum submetidas a diferentes densidades de semeadura.

Verificou-se relação positiva entre a produção de matéria seca total e rendimento de grãos, expressa por tendência linear, embora a constância no rendimento de grãos quando a matéria seca total encontra-se entre 350 e $480 \mathrm{~g} \mathrm{~m}^{-2}$ (Figura 5). Foi observada maior massa seca na densidade de $30 \mathrm{pl}$ $\mathrm{m}^{-2}$ (Figura 1). Resultado semelhante foi observado por Urchei et al. (2000), no entanto, expressa por tendência linear. Porém, essa relação pode não ser coerente para leguminosas, pois a partição de fotossintatos entre os diferentes órgãos da planta possui maior relevância do que o total de matéria seca produzida (Stone \& Pereira, 1994).

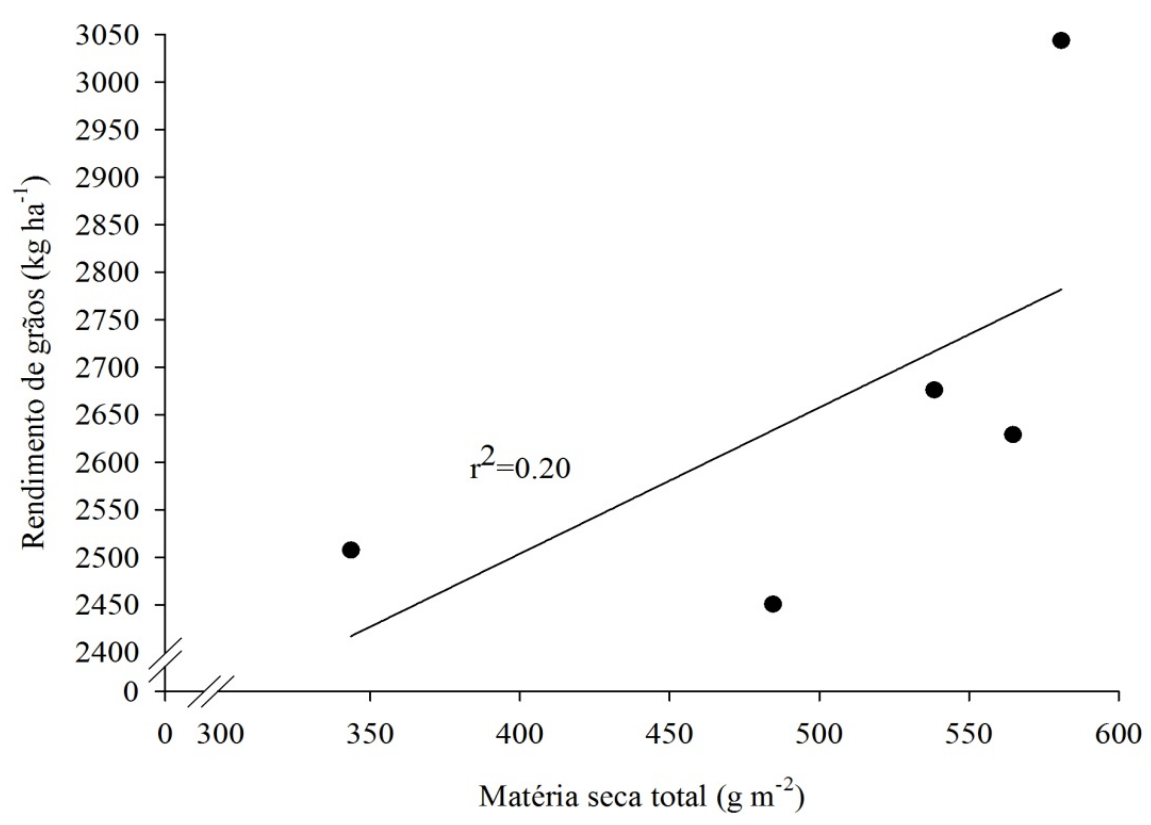

FIGURA 5. Rendimento de grãos $\left(\mathrm{kg} \mathrm{ha}^{-1}\right)$ em função da matéria seca total $\left(\mathrm{g} \mathrm{m}^{-2}\right)$ de plantas de feijão, submetidas a diferentes densidades de semeadura. 
As curvas indicativas de taxa de crescimento da cultura (TCC) em relação às diferentes DS indicam que a MST é influenciada diretamente pela TCC. Observou-se que as plantas submetidas às maiores $D S$, de 35 e $40 \mathrm{pl} \mathrm{m}^{-2}$, apresentaram as menores taxas de crescimento das cultura (Figura 7), devido à maior competição por nutrientes, água e radiação solar, em decorrência do maior número de plantas por área (Medeiros et al., 2000). Já para a densidade de $20 \mathrm{pl} \mathrm{m}^{-2}$ a TCC também foi menor,
SILVA, R.S., et al. Análise de crescimento em...

pois o reduzido número de plantas por área impossibilita a completa exploração dos recursos disponíveis no ambiente. A DS de 25 e $30 \mathrm{pl} \mathrm{m}^{-2}$ proporcionam a melhor harmonia entre as plantas de modo que o aproveitamento dos recursos disponíveis para seu desenvolvimento são maiores, o que contribuiu para o aumento da taxa de crescimento destas plantas.

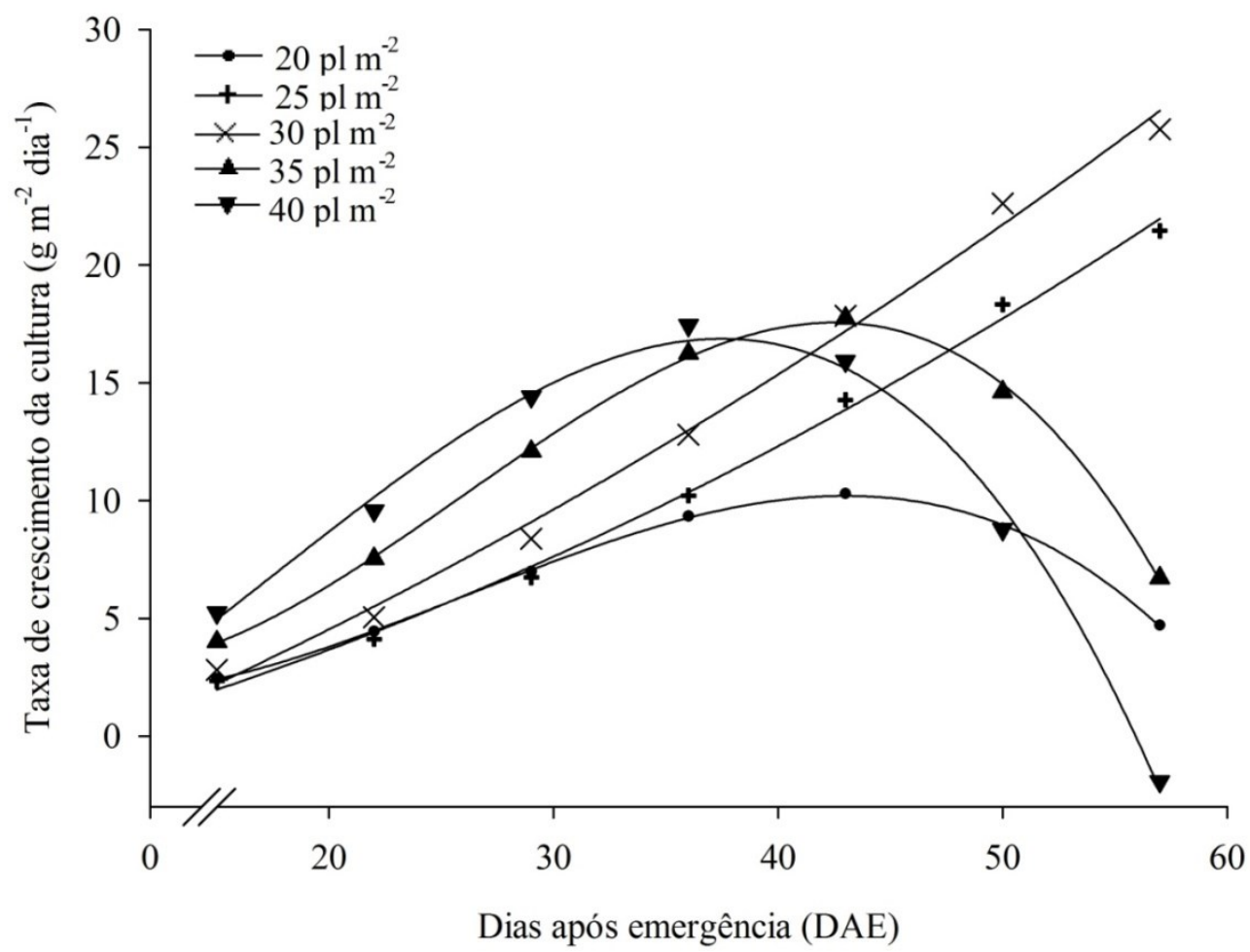

FIGURA 7. Taxa de crescimento da cultura $\left(\mathrm{g} \mathrm{m}^{-2} \mathrm{dia}^{-1}\right)$ de plantas de feijão comum submetidas a diferentes densidades de semeadura.

A taxa de crescimento relativo (TCR) apresentou os maiores valores, para todas as DS, no período inicial de desenvolvimento da cultura, seguido de tendência de redução gradual (Figura 8), já que a TCR está relacionada com o aumento da competição entre as plantas pelos fatores ambientais como luz, água e nutrientes (Ramesh et al., 2000). Além disso, a consequente redução da TCR com o desenvolvimento da cultura pode ser explicada em virtude do aumento no auto-sombreamento e produção de órgãos não fotossintetizantes, como vagens e grãos (Urchei et al., 2000; Jauer et al., 2003) que atuam apenas como dreno dos fotoassimilados e pela ocorrência de maior atividade respiratória (Barreiro et al., 2006). Porém, verificou-se que as DS de 25 e $30 \mathrm{pl} \mathrm{m}^{-2}$ apresentaram quedas menos acentuadas em relação às demais $D S$ a partir dos $35 \mathrm{DAE}$, resultante da menor competição interespecífica pelos recursos do meio. Este resultado indicou o rápido crescimento inicial, fato este, adequado e desejável em lavouras de feijão, já que desse modo às plantas estarão menos predispostas a estresses.

$A$ variação da razão da área foliar (RAF) submetida a diferentes densidades de semeadura apresentou maiores valores até os 30 DAE (Figura 9), pois nessa fase os fotoassimilados são direcionados para a produção de órgãos vegetativos, como as folhas, que são órgãos fotossintetizantes, de tal forma que a relação entre área foliar e matéria seca seja maior. A redução acentuada após esse período é devido ao direcionamento dos fotoassimilados para a formação de gemas floríferas, vagens e grãos (David et al., 2007). Esse maior direcionamento para órgãos reprodutivos é evidente ao analisarmos a Tabela 2 , em que na DS de $30 \mathrm{pl} \mathrm{m}^{-2}$ apresentou maior média grãos por vagens, embora não tenha diferido significativamente dos demais tratamentos. 
SILVA, R.S., et al. Análise de crescimento em...

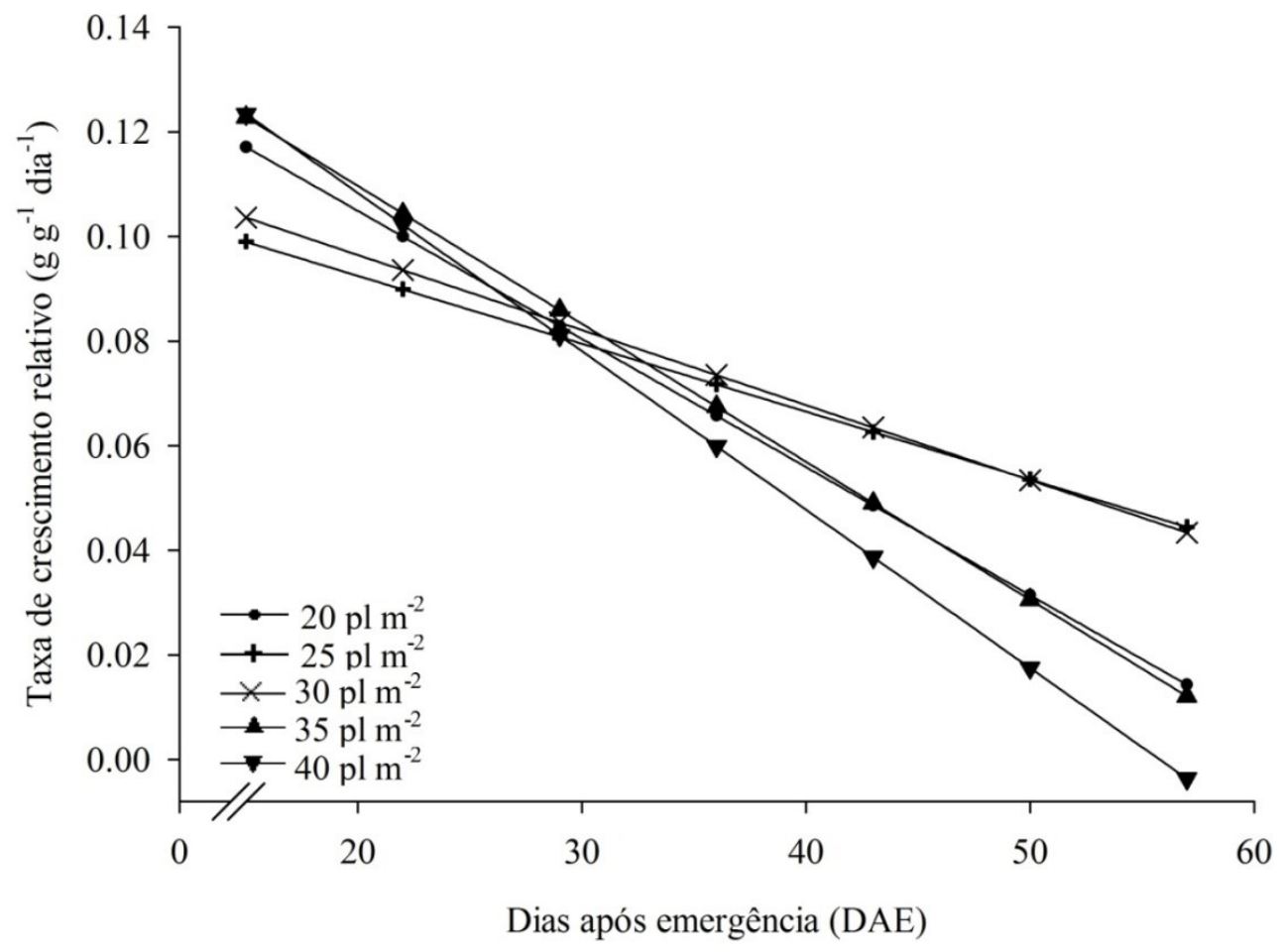

FIGURA 8. Taxa de crescimento relativo $\left(\mathrm{g} \mathrm{g}^{-1} \mathrm{dia}^{-1}\right)$ de plantas de feijão comum submetidas a diferentes densidades de semeadura.

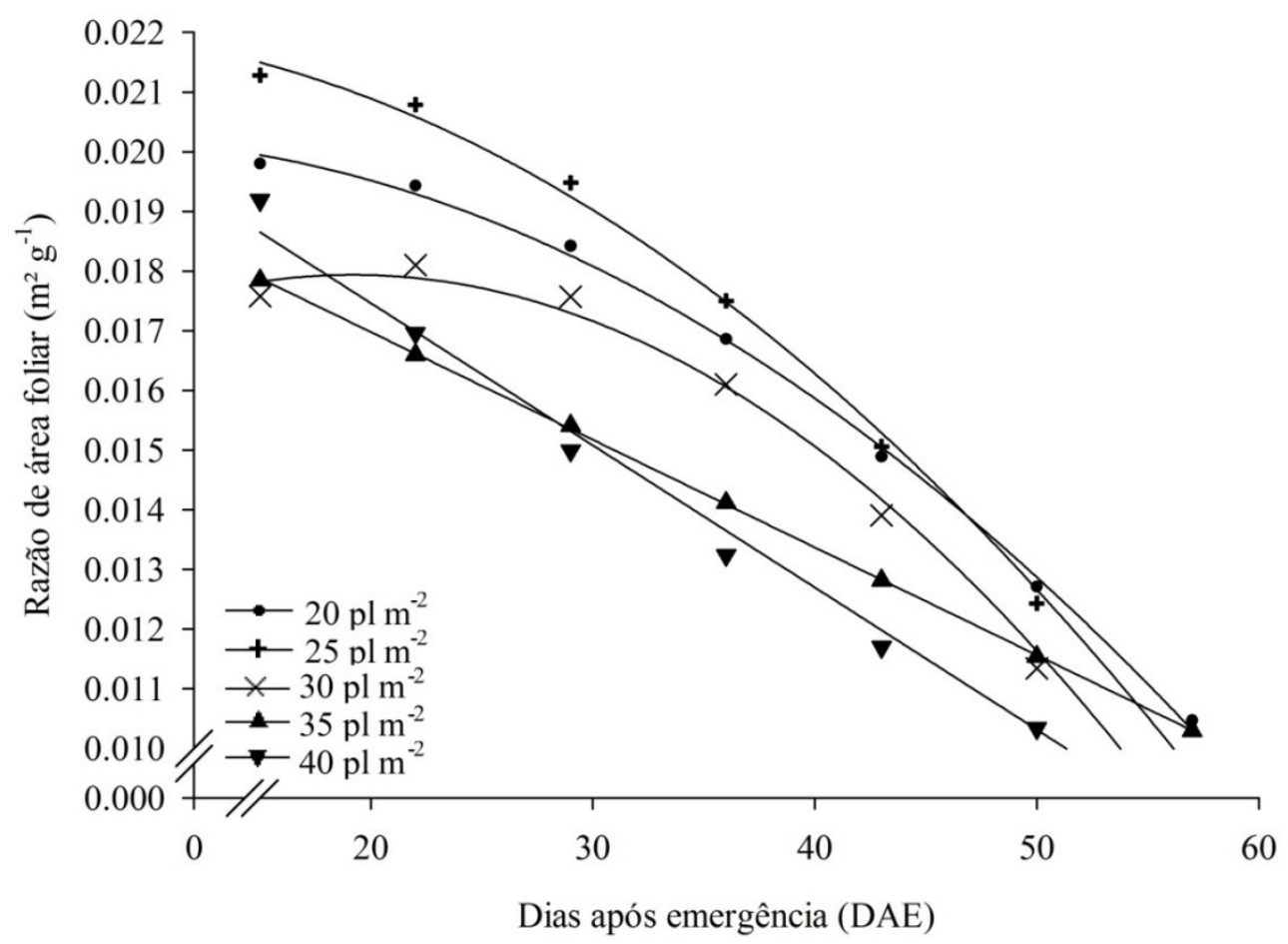

FIGURA 9. Razão da área foliar $\left(\mathrm{m}^{2} \mathrm{~g}^{-1}\right)$ de plantas de feijão comum submetidas a diferentes densidades de semeadura. 
A variação da razão da área foliar (RAF) submetida a diferentes densidades de semeadura apresentou maiores valores até os 30 DAE (Figura 9), pois nessa fase os fotoassimilados são direcionados para a produção de órgãos vegetativos, como as folhas, que são órgãos fotossintetizantes, de tal forma que a relação entre área foliar e matéria seca seja maior. A redução acentuada após esse período é devido ao direcionamento dos fotoassimilados para a formação de gemas floríferas, vagens e grãos (David et al., 2007). Esse maior direcionamento para órgãos reprodutivos é evidente ao analisarmos a Tabela 2, em que na DS de $30 \mathrm{pl} \mathrm{m}^{-2}$ apresentou maior média grãos por vagens, embora não tenha diferido significativamente dos demais tratamentos.

Também foi possível observar que a RAF da DS de $30 \mathrm{pl} \mathrm{m}^{-2}$ foi a menor aos 57 DAE, apesar de ter apresentado a maior matéria seca total na mesma época (Figura 9). Urchei et al. (2000), encontraram resultados semelhantes, atribuindo tais resultados à maior eficiência das folhas na conversão de energia luminosa e $\mathrm{CO}_{2}$ em matéria seca. Esse resultado relatado por Urchei et al. (2000) confirma resultados já discutidos a respeito da matéria seca (Figura 1). Dessa forma, esse tratamento destaca-se novamente por apresentar maior eficiência no aproveitamento dos recursos do meio.

Para as variáveis rendimento de grãos, peso de mil grãos, número de grãos por vagem,
SILVA, R.S., et al. Análise de crescimento em...

número de vagens por área, não foi observada diferença significativa entre os tratamentos (Tabela 2). Entretanto, tendo em vista os resultados discutidos anteriormente em relação à DS de $30 \mathrm{pl} \mathrm{m}^{-2}$, como, por exemplo, em relação à matéria seca total (Figura 1), taxa assimilatória líquida (Figura 4), taxa de crescimento da cultura (Figura 7), taxa de crescimento relativo (Figura 8 ) e razão de área foliar (Figura 9) esta DS apresentou maior número de grãos por vagem e o maior rendimento de grãos. A superioridade no rendimento de grãos pode ser explicada, principalmente, pela maior taxa assimilatória líquida (Figura 4), pois esta proporcionou fotoassimilados em maior quantidade para formação de vagens e grãos, o que refletiu no rendimento de grãos (Figura 6).

Dessa forma, é possível notar a plasticidade da cultura do feijão comum em relação às diferentes densidades de semeadura, visto que o rendimento de grãos não diferiu entre os diferentes tratamentos.

\section{CONCLUSÕES}

A utilização de maiores densidades de semeadura diminui a eficiência da fotossíntese, provocando diminuição da TAL e, consequentemente, menor acúmulo de matéria seca total.

O IAF atinge o valor máximo no período entre o florescimento e formação de vagens.

$\mathrm{Na}$ densidade de semeadura de 30 plantas $\mathrm{m}^{-2}$ há aumento na MST, TCC, TCR e TAL.

TABELA 1. Teores de N (\%), P(\%), $K(\%)$, Ca (\%) e Mg (\%) foliar de feijão comum em função de diferentes densidades de semeadura.

\begin{tabular}{cccccc}
\hline $\mathrm{DS}\left(\mathrm{pl} \mathrm{m}^{-2}\right)$ & $\mathrm{N}(\%)$ & $\mathrm{P}(\%)$ & $\mathrm{K}(\%)$ & $\mathrm{Ca}(\%)$ & $\mathrm{Mg}(\%)$ \\
\hline 20 & 3,20 & 0,29 & 3,69 & 1,60 & 0,43 \\
25 & 4,22 & 0,46 & 4,52 & 1,51 & 0,41 \\
30 & 4,07 & 0,48 & 4,24 & 1,75 & 0,45 \\
35 & 3,34 & 0,36 & 3,13 & 1,64 & 0,36 \\
40 & 3,78 & 0,38 & 3,13 & 1,68 & 0,38 \\
\hline Média & 3,72 & 0,39 & 3,74 & 1,63 & 0,40 \\
\hline
\end{tabular}

TABELA 2. Número médio de vagens por planta, grãos por vagem e peso médio de mil grãos em função de diferentes densidades de semeadura.

\begin{tabular}{cccc}
\hline $\mathrm{DS}\left(\mathrm{pl} \mathrm{m}^{-2}\right)$ & ${\text { Vagens } \mathrm{m}^{-2}}^{\mathrm{n}}$ & Grãos vagem $^{-1}$ & PMS $(\mathrm{g})$ \\
\hline 20 & $308^{\mathrm{ns}}$ & $4,0^{\mathrm{ns}}$ & $228,4^{\mathrm{ns}}$ \\
25 & 296 & 4,0 & 236,6 \\
30 & 343 & 5,0 & 213,1 \\
35 & 300 & 3,0 & 235,7 \\
40 & 352 & 3,0 & 224,7 \\
\hline Média & 11 & 4,0 & 227,7 \\
\hline
\end{tabular}

ns não-significativo pelo teste $\mathrm{F}$. 
SILVA, R.S., et al. Análise de crescimento em...

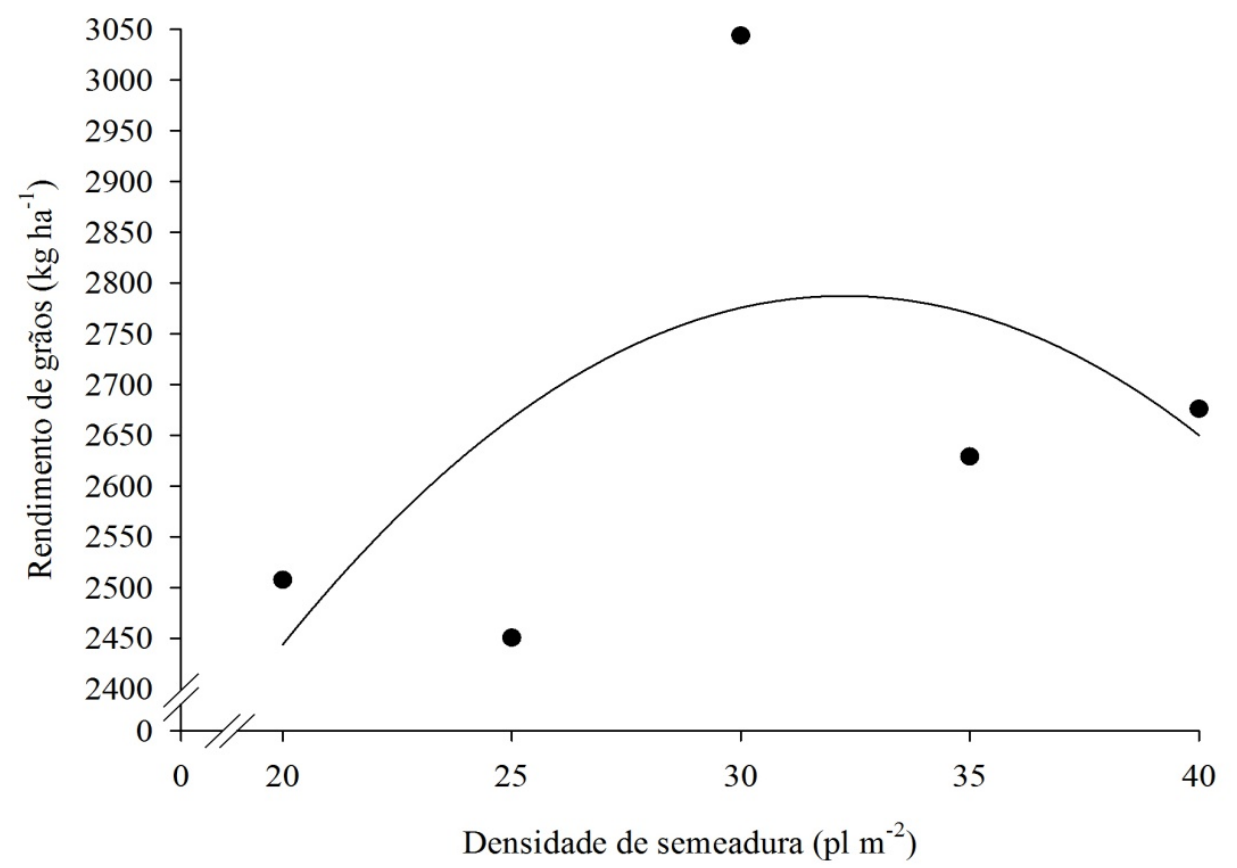

FIGURA 6. Rendimento de grãos $\left(\mathrm{kg} \mathrm{ha}^{-1}\right)$ em função das diferentes densidades de semeadura $\left(\mathrm{pl} \mathrm{m}^{-2}\right)$.

\section{REFERÊNCIAS}

1. BARREIRO, A. P.; ZUCARELI, V.; ONO, E. O.; RODRIGUES, J. D. Análise de crescimento de plantas de manjericão tratadas com reguladores vegetais. Bragantia, v. 65, n. 4, p. 563-567, 2006.

2. BENINCASA, M. M. P. Análise de crescimento de plantas: noções básicas. Jaboticabal: FUNEP, 2 ed., 2003. 42p.

3. BHERING, S.B., SANTOS, H.G. DOS, BOGNOLA, I.A., CÚRCIO, G.R., MANZATTO, C.V., CARVALHO JUNIOR, W. de, CHAGAS, C. da S., ÁGLIO, M. L. D., SOUZA, J. S. de. Mapa de solos do Estado do Paraná: legenda atualizada. Rio de Janeiro: EMBRAPA/IAPAR. 2008. 74p.

4. BRIGHENTI, A. M. et al. Análise de crescimento de bótipos de amendoim-bravo (Euphorbia heterophylla) resistente e susceptível aos herbicidas inibidores de ALS. Planta Daninha, v. 19, n. 1, p. 51-60, 2001.

5. CHRISTOFFOLETI, P. J. Análise comparativa de crescimento de bótipos de picão-preto (Bidens pilosa) resistente e susceptível aos herbicidas inibidores de ALS. Planta Daninha, v. 19, n. 1, p. 75-84, 2001.

6. DAVID, E. F. S.; BOARO, C. S. F.; MARQUES, M. O. Desenvolvimento e rendimento de óleo essencial de menta (Mentha x Piperita L.) cultivada em solução nutritiva com diferentes níveis de fósforo. Biotemas, v. 20, n. 2, p. 15-26, 2007.

7. ERASMO, E. A. L.; BIANCO S.; PITELLI R. A. Estudo sobre o crescimento de fedegoso. Planta Daninha, v. 15, n. 2 , p. 170-179, 1997.

8. JAUER, A.; DUTRA, L. M. C.; ZABOT, L.; LUCCA FILHO, O. A.; LOSEKANN, M. E.; UHRY, D.; STEFANELO, C.; FARIAS, J. R.; LUDWIG, M. P. Análise de crescimento da cultivar de feijão pérola em quatro densidades de semeadura. Revista da FZVA, v. 10, n. 1, p. 1-12, 2003.

9. LOOMIS, R. S.; CONNOR, D. J. Ecología de cultivos - Productividad y manejo en sistemas agrarios. Ediciones Multi-Prensa, México, p. 285-318, 2002.

10. MEDEIROS, G. A. de; ARRUDA, F. B.; SAKAI, E.; FUJIWARA, M.; BONI, N. R. Crescimento vegetativo e coeficiente de cultura do feijoeiro relacionados a graus-dia acumulados. Pesquisa Agropecuária Brasileira, v. 35, n. 9, p. 1733$1742,2000$.

11. NÓBREGA, J. Q.; RAO, T. V. R.; BELTRÃO, N. E. M.; FILHO, J. F. Análise de crescimento do feijoeiro submetido a quatro níveis de umidade do solo. Revista Brasileira de Engenharia Agrícola e Ambiental, v. 5, n. 3, p. 437-443, 2001.

12. PORTES, T. A.; CASTRO Jr., L. G. de; Análise de crescimento de plantas: um programa computacional auxiliar. Revista Brasileira de Fisiologia Vegetal, v. 3, n. 1, p. 53-56, 1991.

13. R Development Core Team. R: A language and environment for statistical computing. $R$ Foundation for Statistical Computing, Vienna, Austria. 2010.

14. RAMESH, P. Effect of different levels of drought during the formative phase on growth parameters and its relationship with dry matter accumulation in sugarcane. Journal Agronomy e Crop Science, v. 185, p. 83-89, 2000

15. RODGERS, C. O.; BARNEIX, A. J. Cultivar differences in the rate of nitrate intake by intact wheat plants as related to growth rate. Physiologia Plantarum, v. 72, p.121-126, 1988.

16. SHIMADA, M. M.; ARF, O.; SÁ, M. E. de. Componentes do rendimento e desenvolvimento do feijoeiro de porte ereto sob diferentes densidades populacionais. Bragantia, v. 59, n. 2, p. 181-187, 2000.

17. SILVA, M. R. M.; MARENCO, R. A. Crescimento de Ischaemum rugosum sob três níveis de sombreamento. Planta Daninha, v. 18, n. 2, p. 187-198, 2000. 
SILVA, R.S., et al. Análise de crescimento em...

18. SPITTERS, C. J. T; KRAMER, T. Differences between spring wheat cultivars in early growth. Euphytica, v. 35, p. 27392, 1986.

19. STONE, L. F.; PEREIRA, A. L. Sucessão arroz-feijão irrigados por aspersão: efeitos de espaçamento entre linhas, adubação e cultivar no crescimento, desenvolvimento radicular e consumo d'água do feijoeiro. Pesquisa Agropecuária Brasileira, v. 29, n. 6, p. 939-954, 1994.

20. TEIXEIRA, I. R.; ANDRADE, M. J. B.; CARVALHO, J. G. de; MORAIS, A. R. de; CORREAA, J. B. D. Resposta do feijoeiro (Phaseolus vulgaris L. Cv. Pérola) a diferentes densidades de semeadura e doses de nitrogênio. Ciência Agrotécnica, v. 24, n. 2, p. 399-408, 2000

21. URCHEI, M. A.; RODRIGUES, J. D.; STONE, L. F. Análise de crescimento de duas cultivares de feijoeiro sob irrigação, em plantio direto e preparo convencional. Pesquisa Agropecuária Brasileira, v. 35, n. 3, p. 497-506, 2000.

22. VALERIO, C. R.; ANDRADE, M. J. B.; FERREIRA, D. F. Comportamento das cultivares de feijão aporé, carioca e pérola em diferentes populações de plantas e espaçamentos entre linhas. Ciência Agrotécnica, v. 23, n. 3, p. 515528, 1999.

23. VIDAL, R. A; TREZZI, M. M. Análise de crescimento de biótipos de leiteira (Euphorbia heterophylla) resistentes e suscetível aos herbicidas inibidores da ALS. Planta Daninha, v. 18, n. 3, p. 427-433, 2000. 